\title{
Factors That Affect the Growth of Micro and Small Scale Enterprises in DebreBerhan Town
}

\author{
Fekade Getabil Habtewold \\ Department of Statistics, College of Natural and Computational Science, DebreBerhan University, DebreBerhan, Ethiopia \\ Email address: \\ feka_get2002@yahoo.com \\ To cite this article: \\ Fekade Getabil Habtewold. Factors That Affect the Growth of Micro and Small Scale Enterprises in DebreBerhan Town. American Journal \\ of Theoretical and Applied Statistics. Vol. 8, No. 4, 2019, pp. 147-156. doi: 10.11648/j.ajtas.20190804.13
}

Received: July 2, 2019; Accepted: July 30, 2019; Published: August 23, 2019

\begin{abstract}
Micro and Small Enterprises (MSEs) in DebreBerhan town does not show necessary growth level and some of the enterprises ceased from market in their infant age. Hence, this study conducted with the objective of assessing factors affecting growth of micro and small enterprises in DebreBerhan town. The study has used both descriptive and explanatory research designed. Data for the analyses collected through questionnaire and focus group discussions. The study has used stratified random sampling technique to select 109 MSES from 1511 fond in DebreBerhan town. The study has used correlation and regressions to establish the relationship between variables. Correlation coefficients revealed a significant relationship between the factors and growths of MSEs (current capital). Variables such as initial capital, access of infrastructure, technology use, habit of receiving feedbacks from customer, profitability of business and government motivation are positively influence to growth of MSEs (profit). Hence improving those variables increase growth of MSEs (current capital). Multiple regression analysis has also revealed that $60.6 \%$ the variation in response variable (current capital) is explained by predictor variables and improving those variables increase growth of MSEs (capital). The study recommends that MSEs Office could be transparent at the time of allocating the working place to the MSEs, better to design close supervisor of MSEs and linking the MSEs with other private contractors working around DebreBerhan town, support the establishment and strength of business development services. Moreover, in order to reduce the influence of factors on growth of MSEs, policy makers and the service provider institutions need to consider and revise the extent, intensity, and quality of support and their linkages.
\end{abstract}

Keywords: Micro and Small Scale Enterprises, Growth of Current Capital, DebreBerhan Town

\section{Introduction}

\subsection{Background of the Study}

Micro and Small Enterprises (MSEs) have become engines of poverty reduction, employment creation and business development among others in various countries worldwide [5]. In the current global economy, micro and small enterprises progressively being regarded as powerful engines for economic performance and development of most economies [8]. Industrial development policy authorities in most developing countries globally have realized the substantial contribution made by MSEs towards attainment of sustainable local economic development and poverty reduction through creation of job opportunities [21].

Growth of MSEs sector is closely associated with the performance of the nation and their contribution in each nation economy [12]. The importance and emphasis of MSEs has been draw attention to the mind of policy maker, planer and industry because of a society is not through the large scale but through individual and small initiatives by visionary from MSEs, and they are base for shift form agrarian to industrial knowledge base [11].

In Africa the MSE sector provides certain benefits to the economy, key among them is the recognized potential of the MSE sector to generate incomes and provide jobs to a large number of peoples [7].

Similarly, in Ethiopia Micro and small enterprises (MSEs) play crucial role for socio-economic development and serves as vehicles for employment opportunities and ways of enhancing wealth creation by support the economic growth [10]. They have become significant employment contributors and can function successfully in many areas of Ethiopia. However, their effectiveness depends on the nature, 
performance, and productivity level of employment and available resource. Limited access to financial services, lack of partnership and networking, absence of technical and business skills among other are major obstacles in the sector.

In line with the country strategy government of Amhara regional state promotes the development of Micro and small enterprises in order to generate income and provide job opportunity for unemployment. According to DebreBerhan town MSEs Development and Construction annual report, Micro and small scale enterprises created employment opportunities for 3497 peoples in sectors such as Manufacturing, construction, trade, urban agriculture and service [18].

In DebreBerhan Micro and Small Enterprises Development Office (DBMSEDO) established in 2007, with responsibility to promote and facilitate the growth of MSEs in order to enable them to play their role in the economy [19] Micro and small enterprises in DebreBerhan town plays essential function in solving unemployment and provide job opportunities to those graduated from university and TVET. However, the growth of micro and small enterprises in DebreBerhan town was not significant as expected.

\subsection{Statement of the Problem}

Micro and small enterprise account for the vast majority of enterprise and contributed major share to employment and economy growth in the European countries, Japan and US [15]. Similarly, many of the countries in Sub-Saharan Africa reported to have high number of MSEs in the economy [17]. In Ethiopia, Micro small and enterprises (MSEs) have a tremendous potential to generate employment for the majority of the urban labor force [10]. The governmentrevised strategy strives to create an enabling environment for MSEs through putting in place a national strategy framework and coordinated programmes at Federal, Regional, and Local levels. Several studies have been identifying factors affecting the growth of Micro and small enterprises in other region of Ethiopia such as Addis Ababa, Hawassa, Mekele and Bahirdar [3, 6, 14].

For instance, study conducted by [1], utilized multiple regression analysis and the finding indicated, external factors and internal factors affect the growth of micro and small enterprises (MSEs). He mentioned external factor includes government motivation, infrastructure factors and technological access and internal factors such as initial capital, skills and managing. His study only focused on manufacturing sectors particularly in textile and garment, food processing and wood and metal work and recommended for further study factors affecting the growth of micro and small enterprises including other sectors such as construction, urban agriculture and trade sectors.

So far, significant number of micro and small enterprises in DebreBerhan town does not show necessary growth level and some of the enterprises ceased from market in their infant age. According to the data from DebreBerhan town Micro and small enterprises office (2014), from total 1591MSEs, 80 MSEs are failed to continue their operations at the end of the year [18]. This motivated the researcher to undertake the study.

Study conducted by [4] in DebreBerhan town on Challenges and opportunities of micro and small scale enterprises using descriptive analysis, result showed that, factors such as environmental, financial, human resource and managerial as well as market related factors constraining the growth of MSEs. His research question focused on internal and external factors hindering the growth of MSEs; however, the study does not clearly indicate those of factors. In addition, his study has not indicated clearly measurement of growth of MSEs. Therefore, the major focus of this research was factors affecting the growth of Micro and small enterprises of all sectors such as construction, manufacturing, urban agriculture, trade and service.

Consequently, the following basic questions are expected to be addressed.

1. What are the major factors that micro and small-scale enterprise face in their growth?

2. What are the possible solutions that can be applied to solve the problems?

3. Is the growth of the micro and small-scale enterprises satisfactory or not?

\subsection{Objective of the Study}

\subsubsection{General Objective}

The main objective of the study was to examined factors those determine growth of micro and small-scale enterprise in DebreBerhan town.

\subsubsection{Specific Objectives}

i. To identify major factors that micro and small scale enterprises face to growth in DebreBerhan town.

ii. To analyze whether there is relationship between the growth of micro and small enterprise and the major factors faced by MSEs, in DebreBerhan town.

iii. To provide predictive models for the future growth of micro and small scale enterprises,

iv. To investigate whether the growth of the MSEs is satisfactory or not in DebreBerhan town.

\subsection{Significance of the Study}

Findings from this study may help academicians for further study in the area by providing a deeper understanding of the critical factors that affect the growth of MSEs. In addition, the regional government uses the findings of this study to overcome critical factors that affect the growth of MSEs. Moreover, the findings of this study may help the policy makers and financial institutions in consideration to areas where the strategies should be focused so as effectively promote MSEs growth.

\section{Literature Review}

\subsection{Introduction}

This chapter reviews related literature under different sub- 
topics relevant to the study objectives. This includes definition of Micro and small enterprises (MSEs), measurement of performance of MSEs, contribution of micro and small enterprises to the economic development. It also discusses the theoretical background and empirical study on micro and small-scale enterprises (MSEs) included the factors that influence performance of MSEs such as Finance, marketing work premises, technology, infrastructure, and personal entrepreneurial characteristics on MSEs performance. Finally presents the conceptual framework, which gives a grasp picture of the study.

\subsection{The Definition of Micro and Small Enterprises (MSES)}

The definition of micro and small enterprises around the globe vary from country to country and depend on the phase of economic development as well as their prevailing social conditions. The definition uses number of full time employee total asset, net asset and paid capital, and annual turnover as criteria independently or in combination. According to European Commission's the recommended official definition of micro and small enterprises base on criteria of the number of employees and one of the two financial criteria, such as either the total turnover or total balance sheet. Based on this definition small enterprises has number of employees less than 50 and micro enterprise has less than 10 employees [20]. Similarly, in Africa the definition of Micro and small scale enterprise is differing from countries to countries. For instance, Kenya's definition of micro and small enterprises used two criteria such as number of employees and the company's annual turnover. For enterprises in the manufacturing sector, the definition takes into account the investment in plant and machinery as well as the registered capital. Accordingly, for micro enterprise number of employees less than 10 and annual turnover is not exceeding ksh 500,000 [22].

According to Ethiopian's Federal Micro and Small Enterprises Agency the improved definition of micro enterprises is an enterprise operates with 5 people including the owner and/or their total asset is not exceeding Birr 100,000 under industry and the values of total asset is not exceeding Birr 50,000 for service sector [10].

Hence, the definition of micro and small enterprise given by Ethiopia revised MSE strategy, 2011 used for this study. Accordingly, micro enterprise defined as an enterprise operates with 5 people including the owner and/or their total asset not exceeding Birr 100,000 (one hundred thousand) under industry sector such as manufacturing, construction and mining and the values asset not exceeding Birr 50,000 (fifty thousand) under service sector such as: retailer, transport, hotel and Tourism, ICT and maintenance service. [10].

In similarly way the definition of small enterprises is as an enterprise operates with 6-30 persons and/or with a paid up capital of total asset Birr 100,000 (one hundred thousand) and not exceeding Birr 1.5 million under industry sector and total asset, or a paid up capital is with Birr 50,000 and not exceeding Birr 500,000 under service sector [22].

As already mentioned, micro and small enterprise contribute to the economic growth of a country by providing new jobs, introduction of innovation, simulate competition, aid big business and produce goods and service efficiently [17]. In many countries, there is now a wide recognition of the contribution of micro- and small enterprises (MSEs) to economic growth. In a cross-section of both developed and emerging economies, the contribution of the MSEs sector to total employment, entrepreneurship and innovation cannot be underestimated.

The potential advantages of a dynamic MSEs sector have generated high expectations in many developing countries about the contributions of this sector to job creation and poverty reduction. Add to this the optimism that the full development of the MSEs sector can foster competitiveness in the economy and achieve a more equitable distribution of the benefits of economic growth in both developed and developing economies. Such considerations have motivated many governments to put in place national policies to stimulate the growth of this sector in service, distribution and manufacturing-related economic activities [7].

According, [7] micro and small enterprises in Sub-Saharan sub African countries play a pivotal role in industrial development and restructuring, satisfying rising local demand for services, allowing for increased specialization and supporting larger firms with inputs and services.

Even though most of the firms in developing countries are micro and small enterprises (MSEs) and despite the substantial amount written about the significance of MSEs to developing economy there is limited literature evidence on the contribution of MSEs to economic growth. According to Ethiopian Development Research Institute studies conducted on micro and small enterprises, MSEs sector growth in terms of its contribution to growth domestic product, employment and export and total manufacturing output is mostly unknown [3].

Based on the review of the literature on the study area indicated that there is information gap on the contribution of MSEs Sector all over the economy of the country.

\subsection{MSE'S Policy and Strategy in Ethiopia}

Economic policies, strategies and legal and regulatory frame work are prerequisite in order to create a conductive environment to promote MSE'S. [9] has argued that in Ethiopia deliberate effort to promote MSE'S in relatively a recent phenomenon. During the Derg regime due to its ideology, policies and regulations the environment was not conductive for the private sector. In general, during the Derg regime the legal requirements to obtain license were bureaucratic, and in affect discouraged the participation of MSE'S operators. The tight foreign exchange control and heavy import and rent seeking business community [9].

The 2002 National MSE'S strategy figure out the various policies, structural and institution related problems that constrained the role of the MSE sector in and contribution to national economy. It thus primarily aims at creation enabling legal, institutional and other supportive environments for the development of MSE'S. the specific objectives of the strategy include Facilitating economic growth and bring 
about equitable development, Creating long term (sustainable) jobs, Strengthening cooperation between MSE'S, Providing the basis for medium and large scale enterprises, Promoting exports and Balancing preferential treatment between MSE'S and bigger enterprises. [9].

\subsection{Empirical Study on Factors Affecting Growth of MSEs}

Based on the reviewed of past studies conducted on micro and small enterprise in developing countries there are several factors affect the growth of MSEs. Accordingly, some of empirical studies discussed as follows; [16] analyzed the factors affecting the growth of MSEs in Uganda and, Nigeria using descriptive research design based on a sample of 60 MSEs. The study concluded that environmental constraints such as high taxes, limited access to market, costly and erratic electricity supply and lack of skilled and competent human resources hinder growth of MSE's.

[2] Analyzed the factors affecting the performance of MSEs in in the Jua Kali sector in Nakuru town of Kenya using descriptive and explanatory research design based on a sample of 262 MSEs. The study concluded that factors such as access of finance, marketing, entrepreneurial skills, corruption and infrastructure affect the growth of MSEs sectors.

In Ethiopia, [1] analyzed the factors that affect the growth of MSEs in Addis Ababa using sample household survey data collected in 2011. He used both descriptive data analysis and multiple regression model to identify the factors affecting MSEs. His finding indicated that finance factors, marketing factors, infrastructure factors, technological factors, work premise factors, management factors and entrepreneurial factors hindered the growth of MSEs.

\subsection{Conceptual Framework}

The conceptual framework shows relationships between independent and dependent variables. Since business growth is influenced by some factors, operators need to understand what influences businesses to reach expected growth. The factors can be include government motivation, habit of receiving feedback from customers, profitability, initial capital (access of credit), technology, infrastructure and soon. In line with the study objectives, growth of MSEs, which measured interms current capital, were dependent variable where as the factors affecting MSEs growth, were used as independent variables measured interms (initial capital, government motivation, habit of receiving feedback from customers, profitability of business, technology use, access of infrastructure)

\section{Methodology}

\subsection{Study Area}

DebreBerhan is city and woreda in central Ethiopia. Located in the semien (north) shoa zone of Amhararegion, about 120 kilometers north east of Addis Ababa on the paved highway to dessie, the town has a latitude and longitude of $9^{\circ} 41^{\prime} \mathrm{n} 39^{\circ} \mathrm{e} / 9.683^{\circ} \mathrm{n} 39.533^{\circ} \mathrm{e}$ and it's the administrative center of the semienshoa zone of the Amhara region. so the study is focus on the micro and small-scale enterprises found in DebreBerhan town.

\subsection{Target Populations}

The study has conducted in five Micro and Small-scale enterprises centre owners /operators of Debrebirhan Town. The target population for this study is such as construction enterprises, manufacturing groups, agriculture and transport.

\subsection{Source of Data}

The main sources of data for this study is Primary data which is first hand data and is directly collected from the respondents sampled from the target population by using stratified random sampling techniques and through the well organized and administered questionnaires to gather necessary information Some secondary sources of data were used for this study.

\subsection{Sampling Design and Techniques}

The sampling technique is simple random sampling (SRS) to select the representatives from target population (frame). In this case the units in the populations are numbered from 1 to $\mathrm{N}$. A series of a random number between 1 to $\mathrm{N}$ is then drawn by means of lottery method. At any draw, the process used must give an equal chance of selection at any number in the population but not already drawn.

\subsection{Method of Data Collection}

The method of data collection would be determined by the following factors. Objective of the study, nature information and operational possibility cost. There are different methods of data collection. Among them administrated and direct investigations are the appropriate for this study. Based on the origin of data, statistical data can be classified as primary and secondary data. Among them, this research project would be conducted by using primary source of data; this would be collected information from respondents through some specific questionnaires.

\subsection{Sample Size Determination}

Determining the sample size is very important issue for the precision of the survey. For this study would use stratified sampling is used with proportion allocation to determine the population size of the enterprises. Determining the sample size is the key step on the overall statistical processes. An appropriate sample size means of gaining high precision, accuracy and confidence with minimum cost. There is a sample determination formula, with much better margin error, i.e.0.05. (Godden (2004); (Aczel, Amir, Sounderpandin and Jayavel 2006)) Accordingly:

$$
\text { no }=\frac{(\mathrm{z} \alpha / 2)}{d 2} P q
$$


Where

$$
(\mathrm{Z}=0.5, \mathrm{p}=0.5, \mathrm{q}=0.5, \mathrm{~d}=9 \%)=118 . \text { If } \mathrm{no}<5 \%, \mathrm{no}=\mathrm{n}
$$

But,

$$
\frac{n_{o}}{N}=\frac{118}{1511}=0.078>5 \%(0.005)
$$

so use

$$
n=\frac{n_{o}}{1+\frac{n_{o}}{N}} n=\frac{118}{1+\frac{118}{1511}}=\frac{118}{1.078}=109.4 \approx 109
$$

\subsection{Variables Included in the Study}

The response variable in this study is Current capital, which the capital the MSEs has in the current time and the explanatory variables included in this study are, infrastructure access, initial capital, technology use, profitability of business, habit of receiving feedback from customer, and government motivation.

\subsection{Method of Statistical Data Analysis}

\subsubsection{Descriptive Statistics}

Descriptive statistics consist of the collection, organization, summarization and presentation of data in some meaning full, from such charts, graphs or table. Since variable under study is qualitative variable, the bar graph is appropriate for the study.

\subsubsection{Inferential Statistics}

In this way a set of methods will use to generalize from sample to population by performing hypothesis testing, determining the relationship among estimate variables and making prediction by data inferential methods such as chisquare, multiple linear regression and hypothesis testing.

Multiple Linear Regression Analysis

Multiple linear regressions are a direct extension of simple linear regression. It is Statistical technique that uses several explanatory variables to predict the outcome of a response variable (Current capital). The goal of multiple linear regressions (MLR) is to model the relationship between the explanatory and response variables. Regression Models a mathematical equation provides prediction of values of dependent variable based on the known values of two or more independent variables. A particular form of regression model depends up on the nature of the problem under study and the type of data variables.

Consider the problem of regression when study variable depends on more than one explanatory or independent variables, called as multiple linear regression models. This model generalizes the simple linear regression in two ways. It allows the mean function $\mathrm{E}$ (y) to depend on more than one explanatory variable and to have shapes other than straight lines, although it does not allow for arbitrary shapes.

The linear model:

Let y denotes the dependent (or study) variable that is linearly related to $\mathrm{k}$ independent (or explanatory) variables
$X_{1}, X_{2}, \ldots, X_{k}$ through the parameters $\beta_{1}, \beta_{2}, \ldots, \beta_{\mathrm{k}}$ and we write

$$
Y=\beta_{0}+\beta_{1} X_{1}+\beta_{2} X_{2}+\ldots+\beta_{k} X_{k}+\varepsilon
$$

This is called as the multiple linear regression models. The parameters $\beta_{1}, \beta_{2}, \ldots, \beta_{\mathrm{k}}$ are the regression coefficients associated with $X_{1}, X_{2}, \ldots, X_{k}$ respectively and $\varepsilon$ is the random error component reflecting the difference between the observed and fitted linear relationship. There can be various reasons for such difference, e.g., joint effect of those variables not included in the model, random factors which cannot be accounted in the model etc.

Note that the $\mathrm{j}$ th regression coefficient $\beta_{\mathrm{j}}$ represents the expected change in $y$ per unit change in $\mathrm{j}^{\text {th }}$ independent variable $X_{j}$. Assuming $(\varepsilon)=0$.

Assumptions

i. For any specific value of the independent variable, the values of the $\mathrm{Y}$ variable are normally distributed. (this is called the normality assumption)

ii. There is a linear relationship between the dependent variable and the independent variables. (This is called the linearity assumption.)

iii. The independent variables are not correlated. (This is called the nonmuliticolinearity.)

iv. The values for the $\mathrm{Y}$ variables are independent. (This is called the independence assumption.)

\subsection{Parameter Estimation of the Model}

The model parameter is estimated by using least square estimation method. This is given as $\widehat{\beta}=\left(x^{\prime} x\right)^{-1} x^{\prime} y$. The model of least square estimation is used to estimate regression coefficient in multiple linear regression model. There is a response variable and more than one explanatory variables. Variables of (xi) assume the model has $\mathrm{E}(\varepsilon)=0$, var $(\varepsilon)$ $=\sigma^{2}$ and $\sum\left(\varepsilon_{\mathrm{i}}\right)$ are uncorrelated random variables.

Where, $\mathrm{Y}=\mathrm{nx} 1$ vector of observation

$\mathrm{X}=\mathrm{nxp}$ invertible matrix

$\mathrm{B}=\mathrm{px} 1$ vector of regression coefficients that was estimated from the data.

The model

$$
Y=\beta_{0}+\beta_{1} X_{1}+\beta_{2} X_{2}+\ldots+\beta_{k} X_{k}+\varepsilon
$$

Where: The model also can be expressed as in matrix form $\mathrm{Y}=\mathrm{X} \beta+\varepsilon$

Least square estimator (LSE) of $\beta$ for the multiple linear regression model $\mathrm{Y} i=\mathrm{X} \beta+\varepsilon \hat{\beta}=\left(\mathrm{x}^{\prime} \mathrm{x}\right)^{-1} \mathrm{x}^{\prime} \mathrm{y}$ assuming $\left(\mathrm{x}^{\prime} \mathrm{x}\right)^{-1} \mathrm{x}^{\prime}$ is invertible or non singular matrix $\widehat{\beta}=$ minimize $\mathrm{SSE}$ or sum square of error.

\section{Results and Discussion}

The main objective of this study is assisting to identify factor that determines the Growth of micro and small-scale enterprises in DebreBerhan Town, The data were collected on the respondents of the factor and their activities. The sample size determined for this study was 109 , the analysis was based on the information, and the data obtained from 109 respondents. 


\subsection{Descriptive Analysis About Study Variables}

This technique is mostly employed for describing the characteristics of the sample and the major study variables are displayed in the form of frequency description, percentage, cross tabulation and diagrammatic representation such as bar chart.

The result of the data analysis presented in the table 1 revealed that out of 109 respondents $18(16.5 \%)$ illiterate, 11 (10.1\%) primary, 46 (42.2\%) secondary, 29 (26.6\%) diploma, and $5(4.6 \%)$ the educational level of above. That means most of the educational level are secondary. Concerning the age of the managers the most the enterprises managers are between the age intervals 26-35. that means out of 109 respondents 55 managers are found in this interval.

Table 1. Description of the study variable.

\begin{tabular}{|c|c|c|c|}
\hline Variable & Category of variable & Frequency & Percent (\%) \\
\hline \multirow{4}{*}{ Initial capital } & $5000-15000$ & 5 & 4.6 \\
\hline & $16000-30000$ & 33 & 30.3 \\
\hline & $31000-45000$ & 64 & 58.7 \\
\hline & $>450000$ & 7 & 6.4 \\
\hline \multirow{4}{*}{ Current capital } & $<=125000$ & 4 & 3.7 \\
\hline & $126000-150000$ & 21 & 19.3 \\
\hline & $151000-175000$ & 58 & 53.2 \\
\hline & $>176000$ & 26 & 23.9 \\
\hline \multirow{3}{*}{ Technology use } & High & 6 & 5.5 \\
\hline & Medium & 17 & 15.6 \\
\hline & Low & 86 & 78.9 \\
\hline \multirow{3}{*}{ Government motivation } & High & 4 & 3.7 \\
\hline & Medium & 50 & 45.9 \\
\hline & Low & 55 & 50.5 \\
\hline \multirow{3}{*}{ Profitability of business } & very satisfactory & 8 & 7.3 \\
\hline & Averagely & 14 & 12.8 \\
\hline & Unsatisfactory & 87 & 79.8 \\
\hline \multirow{3}{*}{ Access of infrastructure } & very satisfactory & 7 & 6.4 \\
\hline & Averagely & 29 & 26.6 \\
\hline & Unsatisfactory & 73 & 67.0 \\
\hline \multirow{3}{*}{ Habit of receiving feedback from customer } & High & 3 & 2.8 \\
\hline & Medium & 23 & 21.1 \\
\hline & Low & 83 & 76.1 \\
\hline \multirow{4}{*}{ Age of the managers } & $15-25$ & 31 & 28.4 \\
\hline & $26-35$ & 63 & 57.8 \\
\hline & $36-45$ & 9 & 8.3 \\
\hline & $>=46$ & 6 & 5.5 \\
\hline \multirow{4}{*}{ Education level of the respondent } & Illiterate & 18 & 16.5 \\
\hline & Secondary & 46 & 42.2 \\
\hline & Diploma & 29 & 26.6 \\
\hline & Above & 5 & 4.6 \\
\hline \multirow{4}{*}{ Marital status of the respondent } & Married & 31 & 28.4 \\
\hline & Widowed & 10 & 9.2 \\
\hline & Single & 51 & 46.8 \\
\hline & Divorced & 17 & 15.6 \\
\hline
\end{tabular}

From table 1 the respondents, 31 (28.4\%), 10 (9.2\%), 51 (46.8\%) and $17(15.6 \%)$ were married, widowed, single and Divorced are respectively. From the respondents, $5(4.6 \%)$, $33(30.3 \%), 64(58.7 \%)$ and $7(6.4 \%)$ were the interval 5000 15000 , 16000-30000, 31000-45000,>45000 respectively. That means the initial capital of the enterprise $58.7 \%$ are between 31000 and 45000 including them. Concerning current capital most of the capital is between the intervals $151000-175000$, that means $53.2 \%$. and the profitability of the business is unsatisfactory.

Figure 1 shows that in this study population government motivation is less. That means $55(50.5 \%)$ says Low, 50
$(45.9 \%)$ say medium and $4(3.7 \%)$ says high. the habit of receiving feedback from customer visit is smaller among those with have no customer. That means 83 (76.1\%) says Low and $23(21.1 \%)$ say medium and $3(2.8 \%)$ says high.

\subsection{Inferential Analyses}

Inferential statistics is statistical method that deals with inferring or drawing conclusions about population based on data obtained from limited number of observations that came from the population. Inferential statistics consist of estimation and hypothesis testing. 
Table 2. chi-squared test result among the study variables.

\begin{tabular}{|c|c|c|c|c|}
\hline \multirow{2}{*}{ Explanatory variable } & \multicolumn{4}{|l|}{ Current capital } \\
\hline & Pearson Chi-Square & Value & d.f & Asymp. Sig. (2-sided) \\
\hline Habit of feedback & Pearson Chi-Square & $20.641^{\mathrm{a}}$ & 6 & .002 \\
\hline government motivation & Pearson Chi-Square & $76.349^{\mathrm{a}}$ & 6 & .000 \\
\hline Technology use & Pearson Chi-Square & $20.641^{\mathrm{a}}$ & 6 & .002 \\
\hline Profitability of business & Pearson Chi-Square & $19.200^{\mathrm{a}}$ & 6 & .004 \\
\hline access of infrastructure & Pearson Chi-Square & $5.862^{\mathrm{a}}$ & 6 & .439 \\
\hline initial capital & Pearson Chi-Square & $1.212 \mathrm{E} 2^{\mathrm{a}}$ & 6 & .000 \\
\hline
\end{tabular}

From the results summarized in table 2 the large value of chi-square and small p-value indicated that, there is statistically significant association between explanatory variable such as, habit of feedback, government motivation, technology use, profitability of business, initial capital with the response variable Current capital.

The Multiple Linear Regression Analysis

Multiple linear regressions are a direct extension of simple linear regression. It is Statistical technique that uses several explanatory variables to predict the outcome of a response variable. The goal of multiple linear regressions (MLR) is to model the relationship between the explanatory and response variables.

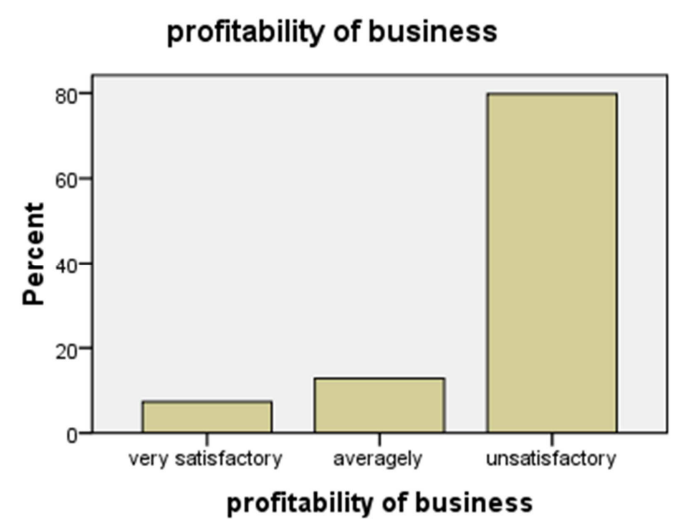

Figure 1. The bar chart of profitability of business.

Table 3. Model summary.

\begin{tabular}{|c|c|c|c|c|c|c|c|c|c|}
\hline \multicolumn{10}{|c|}{ Model Summary } \\
\hline \multirow{2}{*}{ Model } & \multirow{2}{*}{$\mathbf{R}$} & \multirow{2}{*}{ R Square } & \multirow{2}{*}{ Adjusted R Square } & \multirow{2}{*}{$\begin{array}{l}\text { Std. Error of the } \\
\text { Estimate }\end{array}$} & \multicolumn{5}{|l|}{ Change Statistics } \\
\hline & & & & & R Square Change & F Change & df1 & df2 & Sig. F Change \\
\hline 1 & $778^{\mathrm{a}}$ & 606 & 583 & 493 & 606 & 26.119 & 6 & 102 & 000 \\
\hline
\end{tabular}

From the above table 3 we can observe that the R-square and adjusted R-square were good. Because R-square $=0.606$ and adjusted $\mathrm{R}$-square $=0.583$, this implies that $\mathrm{R}$-square is $60.6 \%$ and adjusted R-square is $58.3 \%$. From this value of adjusted R-square $60.6 \%$ (which is greater than $60 \%$ ) the variation in the distribution of the current capital of enterprise is explained by initial capital, government motivation, access of infrastructure, Profitability of business, the habit of receiving feedback from the customer and technology use and $39.4 \%$ of the distribution of current capital is explained by another factors that don't included in this study. Therefore the model for the data that collected from 109 samples from 1511 totals is good fit.

\subsection{The Overall Test of the Model}

The overall goodness of the model would be checked by performing the ANOVA.

Table 4. ANOVA.

\begin{tabular}{lllllll}
\hline Model & & Sum of Squares & Df & Mean Square & F & Sig \\
\hline \multirow{3}{*}{1} & Regression & 38.112 & 6 & 6.352 & 26.119 \\
& Residual & 24.805 & 102 & 243 & \\
& Total & 62.917 & 108 & & \\
\hline
\end{tabular}

From the ANOVA tables, p-value is 0.000 is less than the level of significance $(0.05)$. Therefore, we can conclude that at $5 \%$ level of significance at least one's explanatory variables have significance effect on current capital. The overall model is statistically significance for the data.

Table 5. Testing individual parameter.

\begin{tabular}{|c|c|c|c|c|c|c|}
\hline \multicolumn{2}{|l|}{ Model } & \multicolumn{2}{|c|}{ Unstandardized Coefficients } & \multicolumn{3}{|c|}{ Standardized Coefficients } \\
\hline \multirow{7}{*}{1} & \multirow{2}{*}{ (Constant) } & B & Std. Error & Beta & t & Sig \\
\hline & & -1.003 & 309 & & -3.249 & 002 \\
\hline & initial capital & 626 & 075 & 547 & 8.386 & 000 \\
\hline & government motivation & 502 & 087 & 376 & 5.784 & 000 \\
\hline & habit of feedback & 045 & 104 & 029 & 428 & 669 \\
\hline & access of infrastructure & 295 & 088 & 235 & 3.359 & 001 \\
\hline & profitability of business & 096 & 089 & 075 & 1.078 & 284 \\
\hline
\end{tabular}


The variables such as initial capital, government motivation, access of infrastructure and technology use is significant. This means that their value is less than alpha value. These indicate that they have statistical significance effect on current capital of MSEs. The statistical model that was used in this study is multiple linear regressions model. The mathematical notation of model is given by;

$$
Y=\beta_{0}+\beta_{1} x_{1}+\beta_{2} x_{2}+\beta_{3} x_{3}+\beta_{4} x_{4}+e_{i}
$$

$\mathrm{Y}=-1.003+0.626$ initial capital +0.502 government motivation +0.295 access of infrastructure +0.274 Technology use.

Where;

$\beta 1=0.0626$ indicates keeping other variables constant when the value of the initial capital changes by a unit change in the value of the current capital changes by 0.0626 .

$\beta 2=0.502$ indicates keeping other variables constant when the value of the government motivation changes by a unit change in the value of the current capital changes by 0.502 .

$\beta 3=0.295$ indicates keeping other variables constant when the value of the access of infrastructure changes by a unit change in the value of the current capital changes by 0.295 .

$\beta 4=0.274$ indicates keeping other variables constant when the value of the technology use changes by a unit change in the value of the current capital changes by 0.274 .

\subsection{Regression Diagnosis}

Multi-co-linearity refers to the existence of perfect linear relationship among repressors could be test the presence of multi-co-linearity by variance inflation factor (VIF) is given by: $\frac{1}{1-0.606}=2.534$

The decision is that there is perfect linear relationship among repressors (there is multicolinearity) based on variance inflation factor (VIF). Because of VIF are greater than 10 .

\subsection{Model Adequacy Checking}

This model is used to check whether the major or standard assumptions of multiple linear regression analysis are meeting. This is made through the following.

Residual Analysis: - Analysis of residual is an effective way to discover several type of model adequacy. It is a measure of variability that was left unexplained by the regression model. Thus any departures from the assumptions on the errors should show up in the residuals. Its analysis is effective through plotting. Histogram, Normal probability plot and Scatter plot.

\section{Histogram}

\section{Dependent Variable: current capital}



Figure 2. Histogram diagram.

From figure 2 we can conclude that the error term is normally distributed with mean zero and constant variance. Therefore, normality assumption is show that the error term is assumed to be normally or the heterogeneous of variance exists. Or from figure 2 we observe that the normality assumption is satisfied. This means that residuals of the response variables are normally distributed. This checks the normality assumption of the residual term as well as the normality assumption of the model.
From figure 3 as a statistician, one can conclude that the model becomes normal. Because the plot of the ordered standardized residuals are approximately the same as the ordered normal scores. Under normality assumption, the plot indicates nearly straight line with an intercept of zero and a slope of one (these are the mean and standard deviation of residuals respectively). Generally, the normality assumptions are satisfied. 
Normal P-P Plot of Regression Standardized Residual

Dependent Variable: current capital



Figure 3. The normal p-p plot among the study variables.

\section{Discussion}

The objective of this study was to examine the factors that affect the growth of MSEs in case of DebreBerhan town. In this study only quantitative research are used. The target populations of the study were the total group of MSEs in DebreBerhan town during the study period. Then the stratified sampling technique is used to selected representative samples from the target population.

In this study, primary data were used as source of data. Based on the research objective, English version questionnaires were prepared. One hundred nine (109) respondents were approached stratified sampling technique. The result of this paper indicates that among the respondents' minimum $(<=125000)$ of 4 MSEs and maximum $(>176000)$ of 26 MSEs have current capital.

Moreover, the result of this paper shows that initial capital, technology use, government motivation, habit of feedback and profitability of business does affectthe current capital (have significant factor for current capital) and supports some other papers studied about factors that affect the growth of MSEs, results significant to those factors.

Other studies such that research worked different university and in different years Kenya (2014), Nuwagaba and Nzewi (2013) using descriptive and explanatory research design results significant and a positive relationships so not contradict to for this study results and region of Ethiopia such as Addis Ababa, Hawassa, Mekele and Bahirdar (Weldegbriel, 2012; MUDC survey, 2013; Berihu, Abebaw\&Biruk, 2014). For instance, study conducted by Admasu (2012), utilized multiple regression analysis and the finding indicated, there are significant variables that have a positive and negative relationship respectively so contradict to this study results.
In general to contradict the above some variable could be this caused may be the software used for analysis, total samples used for the study, respondents answer and the categories used for the variables such factors caused these differences.

\section{Conclusions}

The objective of this study is to identify factor that determines the Growth of micro and small-scale enterprises in DebreBerhan Town. Depending up on the finding of this study, the following conclusion is given. This study shows that there is the relationship between the current capital of MSEs and initial capital, government motivation, access of infrastructure, the habit of receiving feedback from the customer and technology use which is positive. This means current capital has direct relationship to those variables but the Profitability of business is negative. This means current capital has indirect relationship to this variable.

This paper indicates that, out of 109 respondents 63 (57.8\%) age of the managers is between 26-35, showing that they are young managers. The education level of this managers $46(42.2 \%)$ are secondary education level, also their marital status about 51 (46.8\%) managers are single. The number of manpower increase from time to time that means the initial man power is averagely 23 and now current manpower was averagely 32 . This indicates the role of MSEs in reduction of unemployment is high.

Generally; the result of the study indicates that micro and small scale business owners have no clear concept of marketing as they prefer to emphasize on proper customer visit. According to the information received from the respondent the government motivation is low, the access of infrastructure is low (unsatisfactory) such as there is problem like, lack of water supply, road construction and lack of light, the initial capital is between $31000-45000$ and the profitability of the business is not satisfactory (unsatisfactory) so, the explanatory variables are significantly associated with response (current capital) variable.

\section{Recommendations}

Explanatory variables such as age of the respondent, sex of the respondent, initial capital (in birr) and government motivation were some of the factors most probable affects growth of micro small scale enterprise. Bearing this in mind we make the following recommendations:

Education should be extended or provided to the owners of micro and small scale enterprises to develop entrepreneurial and managerial skills so that they can plan the operation of their business identify and exploit the opportunities available to them. The owners should be educated on marketing concepts so that they can get clear view of the role of proper customer service. To make effective the business, the owners should facilitate conditions in which the applicant can get sufficient consultancy concerning the nature of the business they want start, location of the business, identification of target customer groups, marketing conditions and ways to 
seek market information.

Generally the analysis revealed that the owners have to develop the habit of seeking feedback from their customer, because lack of awareness about its importance keeping their customer in touch with them, So as to have successful business operation, any business owners should develop customer relationship management.

From the analysis government motivation is low, but government should have to motivate them, it can be through financial support, providing (creating) marketing relationship, giving motivation certificate, providing access of credit (loan), giving training skill (skill development) and soon. Moreover, in order to reduce the influence of factors on growth of MSEs, policy makers and the service provider institutions need to consider and revise the extent, intensity, and quality of support and their linkages.

\section{References}

[1] Admasu A (2012) Factors affecting the performance of micro and small enterprises in Arada and Lideta Sub Cities; Addis Ababa, Master thesis.

[2] Anne, N. K. (2014) Factors Affecting the Performance of Small and Medium Enterprises in the Jua Kali Sector In Nakuru Town, Kenya. IOSR Journal of Business and Management, 16, 80-93. https://doi.org/10.9790/487X16148093.

[3] Berihu Assefa, Abebaw Zerfu, and Biruk Tekle. Identifying Key Success Factors and Constraints of Ethiopia's MSE Development: An Exploratory Research. 2014. EDRI Research Report 18. Addis Ababa: Ethiopian Development Research Institute.

[4] Birhanu 2012, "Determinants of commercial banks profitability:" empirical evidence from the commercial banks of Ethiopia, MSc project paper, Addis Ababa University.

[5] Chittithaworn Chittithaworn (2011). Factors Affecting Business Success of Small \& Medium Enterprises (SMEs) in Thailand, Asian Journal of Social Science doi: $10.5539 /$ ass.v $7 \mathrm{n} 5 \mathrm{p} 180$.

[6] Degefu, D. (2018) Factors That Determine the Growth of Micro and Small Enterprises: In the Case of Hawassa City, Ethiopia. iBusiness, 10, 185-200. doi: 10.4236/ib.2018.104011.

[7] (Fjose, Grunfeld, and Green, 2010). Developing countries about the contributions of sector to job creation and poverty reduction.
[8] Ehresman, (2008). Purpose the concept of total quality management is essential for the success of small business.

[9] Gebrehiwot, (2004). The National Micro and small scale enterprise strategy figure out the various policies, structural and institution related problems that constrained the role of the micro sector in and contribution to national economy.

[10] Government of Federal Democratic Republic of Ethiopia (GFDRE), (2011). MSEs development, support scheme, and implementation strategies. Addis Ababa, Ethiopia.

[11] Hailay Gebretinsae PhD (2007). "Entrepreneurship and Small Business Management", 2nd ed. Mekeleuniversity, Addis Ababa Ethiopia.

[12] ILO (2004), Poverty Challenge in Africa: Placing Decent Employment at the Heart of the Battle, World Employment Report 2004-2005, Geneva.

[13] Mbugua, S. K., Agnes, N. and Ondabu, I. T. (2014) Factors Affecting the Performance of Micro and Small Enterprises in Limuru Town Market Kiambu Coun.

[14] MUDC (2011) Urban sector five years growth and transformation plan (2010/11 2014/15): Addis Ababa.

[15] Muller, P., Gagliardi, D., Caliandro, C., Bohn, N. U. \& Klitou, D. (2014). Final Report-July 2014.

[16] Nuwagaba, A. \& Nzewi, H. (2013). Major Environmental Constraints on Growth of Micro and Small Enterprises in Uganda: A Survey of Selected Micro and Small Enterprises in Mbarara Municipality. International Journal of Cooperative Studies, 2 (1), 26-33.

[17] Woller, G. and Schreiner, M. (2008). Measuring outreach: conceptual workshop proceedings. Washington, DC, USA.

[18] (DMSEDO, 2010). DebreBerhan Micro and Small Enterprises Development Office.

[19] (DMSEDO, 2014). DebreBerhan Micro and Small Enterprises Development Office.

[20] Egbugu, (2011). The major criteria use in the definition of SMEs.

[21] Robert, H. and Jelly, H. (2003). Strength cooperation between micro and small scale enterprise promote export and balances preferential treatment between micro and small scale enterprise and bigger enterprises.

[22] Todaro, and smith, (2008). emphasized the need for coordinating the effort of different enterprises in order to maximize the benefit they can generate from the economic activity. 